\title{
The Design of Rice Direct Seeding Machine
}

\author{
S.F. Ding, Q.X. Li, Q. Huang \\ School of Mechanical and Materials Engineering \\ Jiujiang University \\ 551 Qianjing East Road Jiujiang, Jiangxi, China, 332005
}

\author{
S.F. Ding \\ Key Research Lab for Numerical Control of Jiangxi Province \\ Jiujiang University \\ 551 Qianjing East Road Jiujiang, Jiangxi, China, 332005
}

\begin{abstract}
In order to change the existing status of big turning radius of the large direct seeding machines with diesel and gasoline as fuel and improve the low efficiency and time-consuming condition of the machine driven by human or animal, an electric rice planter was designed. The mechanical parts and circuit design had been finished. The rear wheel shaft, seeding wheel, seeding frame and other key parts had been designed. The charging circuit of the maintenance-free storage battery and the power supply circuit of the DC motor had been given. The main technical parameters of the rice planter as follows, L $*$ B *H: $1700 * 1200 * 1200(\mathrm{~mm})$, row distance* planting distance*width $=250 * 200 * 1000(\mathrm{~mm})$. The rice planter driven by DC motor and maintenance-free battery has a compact structure, a small turning radius, and it can be used in hills and mountainous regions.
\end{abstract}

Keywords-rice direct seeding machine; turning radius; maintenance-free storage battery; DC motor

\section{INTRODUCTION}

Rice direct seeding technology, which makes rice planters sow the rice seeds directly into the field, is a relatively extensive planting pattern; it eliminates the seedlings, seedling up and transplanting, simplifies the operation process, decreases the time, the cost and the seedling bed, and increases the production[1]. The applicable machinery for hills, mountains, which cover more than $45 \%$ of China's territory, is a severe lack where the mechanization level is only about a third of the national average level and most still in the undeveloped stage. This seriously affects the normal labor transfer conditions of agricultural production and restricts the development of comprehensive mechanization of agricultural production [2]. In the south, the situation is similar.

The rice planter was normally operated by a single person, or driven by a large motor traction machine with diesel and gasoline engine as power source. The planter with a diesel often makes the turning radius very big, which makes it not suitable for small, scattered growing areas in hills and mountain; the rice planter operated by a single person could work in the hills and mountains, but it's time-consuming and low-efficient.

To solve the single person-manipulated rice planter's engine problem, electric traction was used to replace human or animal traction with appropriate change to the whole machine structure. The maintenance-free battery was chosen as the power supply and the DC motor as the traction; it changed the time-consuming and low efficiency status. It accords with the requirements of the ecological agriculture development. This development has broken the traditional dynamic design, it is low-carbon, energy-saving, and easy to use.

\section{Mechanical Parts Design}

\section{A. The Main Technical Parameters}

The planter's configurations are listed below.

The motor power: $0.35 \mathrm{KW}$

The body length: $1700 \mathrm{~mm}$ or less

The body width: $1200 \mathrm{~mm}$ or less

The body height: $1200 \mathrm{~mm}$ or less

Row space: $250 \mathrm{~mm}$

Seeding planting distance: $200 \mathrm{~mm}$

Working width: $1000 \mathrm{~mm}$.

\section{B. Working Principle}

When the DC motor is turned on, it drives the small chain wheel to rotate. The latter turns the big chain wheel as the big chain wheel is fastened to the rear shaft. The shaft rotates along with the walking wheel and the seeding wheel. When the walking wheel rotates, the rice planter goes straight and when the seeding wheel rotates, the filling, cleaning, protecting and casting processes are finished from the uniformly distributed sowing boxes in the rack [3]. When the DC motor is turned off, the rice planter stops working. The farmer turns the DC motor on or off by steering the front switch in order to implement the seeding operation and to stop the operation. The rice planter turns left or right through the steering wheel.

\section{Structure Diagram}

The host general structure diagram was shown in Figure 1, including 1 front wheel, 2 front shaft, 3 steering wheel, 4 body, 5 maintenance-free battery,6 DC motor, 7 small chain wheel, 8 chain, 9 big chain wheel, 10 rear axle, 11 seeding wheel, 12 sowing rack .

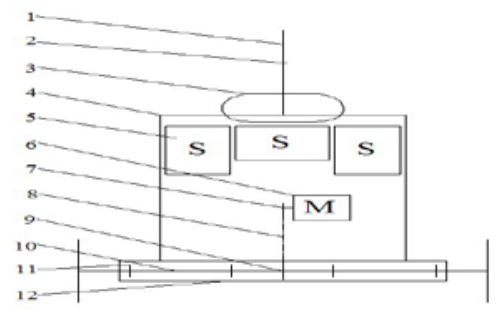

FIGURE I. STRUCTURE DIAGRAM. 
2.

The shape structure of the rice planter was shown in Figure

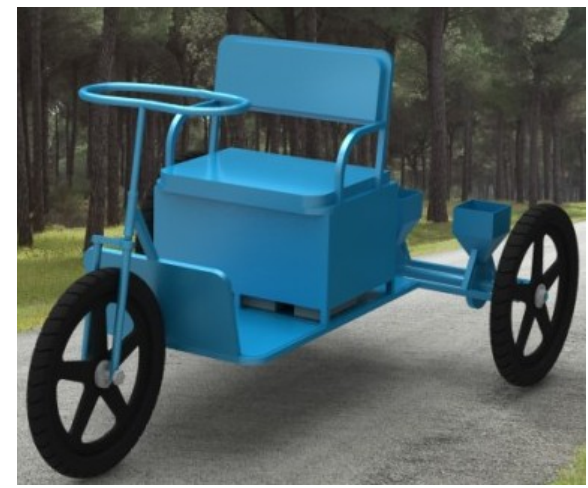

FIGURE II. SHAPE DIAGRAM.

\section{Key COMPONENTS DESIGN}

\section{A. Rear Axle}

The rear axle structure was shown in Figure 3. The power was transferred to the big sprocket in the rear axle. The evenly tightened wheel finished the seeding. The seeding frame was connected with the rear axle. The rear walking wheels were connected on both ends of the shaft which was a stepped one and its material was $45 \#$ steel. There were some operations in the heat treatment of the shaft: the tempering after hardening could improve its hardness and strength, and the plasticity and impact toughness as well [4].

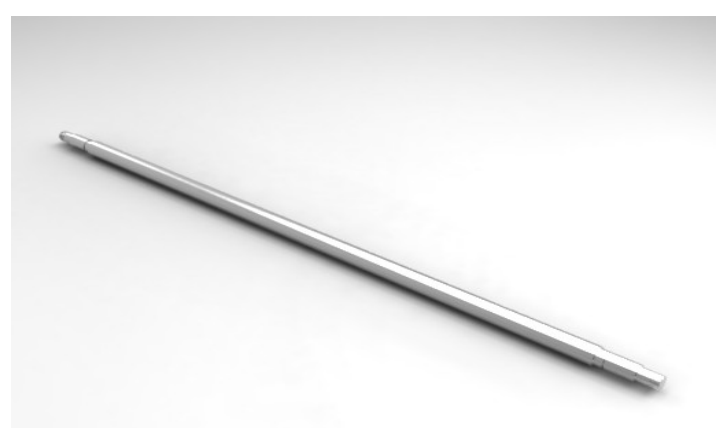

FIGURE III. REAR WHEEL SHAFT.

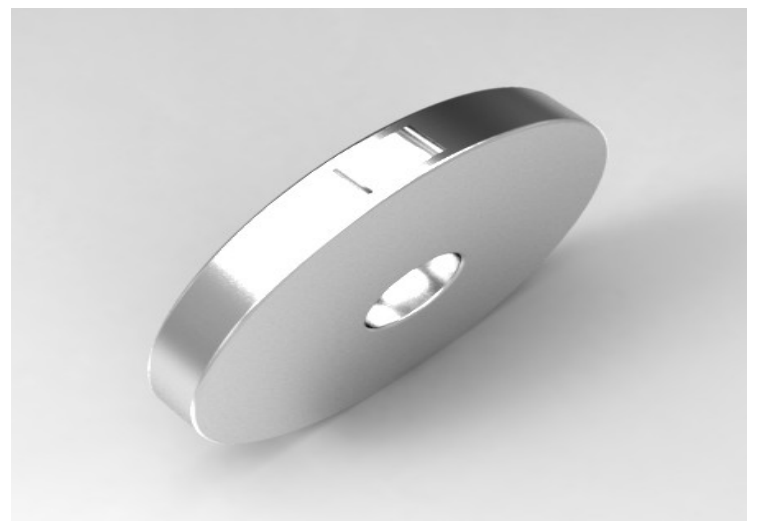

FIGURE IV. SEEDING WHEEL.

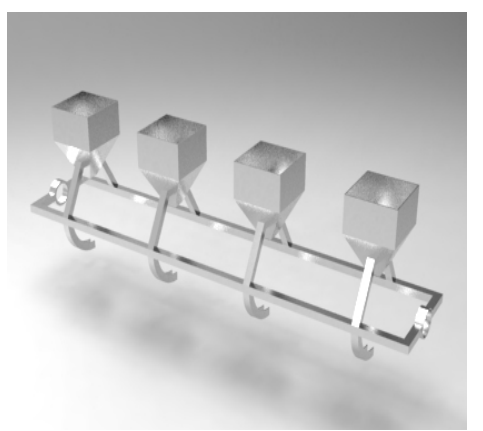

FIGURE V. PLANTING FRAME.

\section{B. Seeding Wheel}

The seeding wheel's main function is filling seeds' and cleaning; the wheel structure was shown in Figure 4. The device has a simple structure and a low cost. The wheel was fastened in the rear axle and its inner diameter is the same to the rear axle; there are two eye sockets uniformly distributed on the cylindrical; the seeding row distance of main technical parameters is $200 \mathrm{~mm}$, so the outer diameter is $127 \mathrm{~mm}$; the seed spacing of main technical parameters is $250 \mathrm{~mm}$ and the seeding wheels are uniformly located in the rear axles.

\section{Seeding Frame}

There were evenly distributed seeding boxes and seeding grooves. The main function of the seeding boxes was storing seeds and releasing seeds, while the main function of the seeding grooves was protecting seeds and casting seeds. Its structure was shown in Figure 5. This device is connected to the rear axle. When the seeding wheel rotates, the seeds in the boxes fall to the eye sockets and slip to the soil with the seeding wheel rotates under gravity.

\section{ThE CIRCUIT DESIGN}

The motor type was DC motor [5] and it was the power source of the rice planter. The DC motor drove the small chain wheel rotate and made the big chain wheel rotate by chain transmission.

DC motor power came from maintenance-free battery; maintenance-free battery charging circuit was shown in Figure 6.

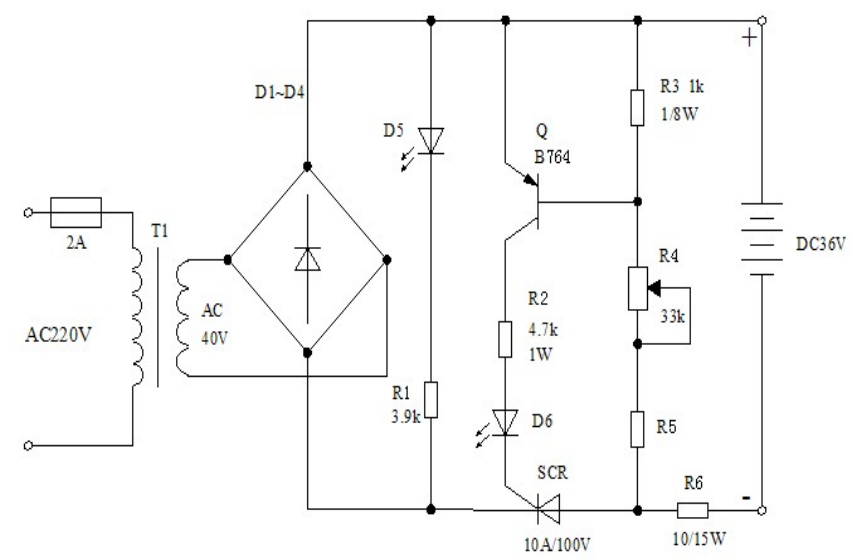

FIGURE VI. MAINTENANCE-FREE BATTERY CHARGING CIRCUIT. 


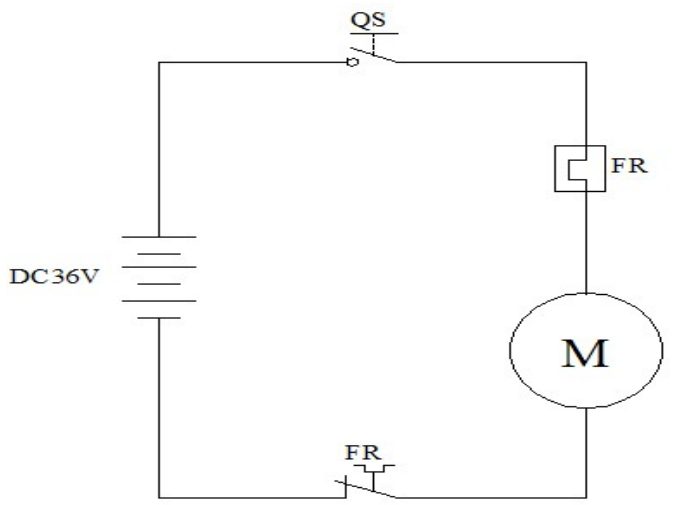

FIGURE VII. THE POWER SUPPLY CIRCUIT OF THE DC MOTOR.

DC motor power supply circuit was shown in Figure 6; the power supply was a $36 \mathrm{v}$ maintenance-free battery and the load was a DC motor. The switch was set between the source and load. A thermal relay was set for the DC motor overload protection [6], and the thermal relay type was JR20 10-14-16A.

\section{SUMMARY}

The rice planter was combined with the DC motor and maintenance-free battery. The DC motor acted as the execution device and the maintenance-free battery as the power unit. The high energy consumption, heavy pollution and high cost condition caused by using diesel and gasoline as the energy source have been improved. The low efficiency condition caused by using man power or animal power as the traction source has also been improved. It accords with the requirement of the ecological agriculture development.

\section{ACKNOWLEDGEMENTS}

This work was financially supported by the Jiangxi Provincial Key Technology R\&D Program of the department of technology (20122BBF60129).

\section{REFERENCES}

[1] Li-qiang Wang, Chong-you Wu, Lian-xing Gao, An-fu Tu, Cheng-qian Jin. The Paddy Planting Status and the Research of Developing Paddy Mechanical Direct Seeding in China. Journal of Agricultural Mechanization Research,2006(3):28-30.in Chinese

[2] Huang-zhen Lv, Xiong-wei Wang, Yun-tao Fan, Bing-nan Yang. Review on Agricultural Machinery Research Progress in 11th Five Year Plan and Direction of Future Development. Agricultural Engineering, 2011,1(2):1-7.in Chinese

[3] Mei Jin, Chun-hua Xia, Chong-you Wu, Wen-yi Zhang. The Present Situation and Trends in Development of Seeding Apparatus of Paddy Planter. Chinese Agricultural Mechanization, 2010, (5):39-42.in Chinese

[4] Zong-ze Wu, Sheng-guo Luo. Course Design Manual for Mechanical Design. Beijing: Higher Education Press, 2006.5. in Chinese

[5] Ze Wang.1GD-40 Type DC Electric Multi-functional Micro Tillage Machine. Journal of Agricultural Equipment Technology, 2007 (2) : 56. in Chinese

[6] Li-jiang Yang. Electric Control Technology in Machine Tool. Beijing: Beijing Institute of Technology Press, 2008.6. in Chinese 